\title{
Effect of Acceptance and Commitment Therapy on the Quality of Life in Infertile Women During Treatment: A Randomized Control Trial
}

\author{
Elahe Rahimi ${ }^{1}$, Mahtab Attarha $^{2^{*}(}$, Abed Majidi $^{3}$
}

\begin{abstract}
Objectives: The present study aimed to investigate the effect of acceptance and commitment therapy (ACT) on the quality of life of infertile women during the treatment.

Materials and Methods: This study was a randomized clinical trial that was conducted on 40 infertile women admitted to the clinics of Arak, Iran. They were selected through a convenience sampling technique and were randomly assigned to intervention $(\mathrm{n}=20)$ and control $(\mathrm{n}=20)$ groups. The Fertility Quality of Life (FertiQoL) Questionnaire was used as a data collection tool, which was completed before and one month after the intervention. The counseling group was provided with eleven 90-minute sessions of ACT twice a week. Then, the data were analyzed using SPSS 23 through the chi-square test and independent samples test.

Results: Based on the results, there was a statistically significant difference between the mean scores of the quality of life in ACT and control groups before and one month after the intervention $(P<0.05)$.

Conclusions: In general, it seems that ACT improves the infertile women's quality of life and this treatment can be used for alleviating the quality of life of these women taking into account the high incidence of infertility.

Keywords: Acceptance and commitment therapy, Quality of life, Infertility, Women
\end{abstract}

\section{Introduction}

Infertility is defined as the failure to achieve a clinical pregnancy after 12 months of regular unprotected sexual intercourse (1) and affects $10 \%-15 \%$ of the couples at reproductive age (2). Inability to become pregnant can be of primary and secondary forms. Primary infertility means delayed pregnancy for couples with no experience of pregnancy in the past while secondary infertility occurs when the couples have a history of fertility but are currently unable to be pregnant (3). According to Onat and Aba (4), the problem may be from the husband (25\%-40\%), wife (40\%-55\%), or both (10\%), or may have an unknown cause (10\%). As a multidimensional issue, infertility is considered as an important threat to health worldwide, and its incidence is about $24.9 \%$ in Iran and $8-10 \%$ in the world (5)

Considering that men and women equally contribute to infertility, infertility is believed to be a woman's problem due to social prejudices and that is why women face more social and familial problems compared to men. Therefore, infertility has more negative effects on the quality of life and anxiety among women when compared to men (6).

In addition, the social stigma of infertility for infertile women is extremely harsh in some countries (7) that makes them socially deprived and thus they receive no appropriate and normal attention. Therefore, infertility influences many aspects of their lives such as their psychological, physical, and social well-being (8).

On the other hand, social and cultural issues like the social and cultural stigma of infertility and various financial, occupational, individual, and collective pressures challenge the process of treatment and infertility experience for infertile people, especially women (6). In one study, $12 \%$ of infertile women stated that their quality of life was low while more than half of them had a desirable quality of life (9).

Although there is no unique and universal definition for the quality of life, there exists a widespread agreement on the multidimensionality of this concept including physical, psychological, and social dimensions (10). It seems that infertility-related issues have a negative effect on the quality of life of couples.

Accordingly, the negative effects of infertility for women, which emerge at individual and social levels, have made the researchers and therapists highly worried about this matter such that they attempted many various interventions to reduce their psychological problems through different approaches (11). One class of these different approaches is those based on acceptance and commitment which focuses on involvement in any experience whether positive or negative and aims to achieve a balanced experience. Acceptance and 
commitment therapy (ACT) is one of the therapies which belongs to the third wave of cognitive behavioral therapies and has its roots in functional contextualism and relational frame theory (12). This therapy focuses on changing the relationship with internal experiences (e.g., thoughts, feelings, memories, and physical senses) instead of altering the content of the experiences directly (13).

In other words, ACT seeks to increase psychological flexibility. In this therapy, psychological flexibility is defined as the ability to contact with the present moment as a human being who is conscious of undesirable thoughts, emotions, and experiences and to change or persist in that behavior in the service of the selected values. This type of flexibility includes 6 core processes as acceptance, mindfulness, contact with the present moment, cognitive diffusion, values, and committed action (14).

The research on the effect of ACT as a therapy for mood disorders confirmed it as an effective treatment for mood, anxiety, and other psychological disorders such as pain and eating disorder $(15,16)$. The ACT is used for treating anger (17), chronic pain, drug abuse, and many other problems as well $(18,19)$. Further, it is an effective therapy for decreasing infertility stress, psychological distress, and infertility-related depression (20), as well as a promising treatment for patients who have failed in vitro fertilization. According to a previous study, ACT improves the relationship between distressed couples and their life satisfaction (21).

Although many studies have so far approved the effectiveness of ACT (15-17,20-22), limited data are available regarding its effect on infertility and the quality of life of women $(20,21,23)$. The present study used fertility quality of life (FertiQoL) Questionnaire, which, to the best of our knowledge, has not so far been utilized in any other similar project. This questionnaire was first designed by Boivin et al to measure the quality of the life of infertile people (23). A critical review of studies attempting to use psychological treatments for helping infertile women to overcome their problems shows that most of the employed methods have not paid enough attention to environmental and cultural congruence needed in the process of treatment. This issue has received serious attention in recent years. Thus, comprehensive and combined treatments are required for integrating the environmental and cultural elements. The results of this research not only create a good setting for studying ACT but also pave the way for other researchers to continue their studies on this therapy. Therefore, the following three hypotheses were proposed in this study in order to fill the current gaps:

1. There is no significant difference between the quality of life before and one month after the intervention in the ACT group.

2. There is no significant difference between the quality of life before and one month after the intervention in the control group.
3. There is no significant difference between the quality of life of the ACT and control groups before and one month after the intervention.

\section{Materials and Methods}

This study was a two-group clinical trial including pretest and post-test (a follow-up one month after the intervention). Statistical and population encompassed all the infertile women living in Arak, Iran and infertile women referring to Omid Rouyn Infertility Center in Arak in the summer and fall of 2016, respectively. Forty infertile women were selected through convenience sampling technique based on inclusion criteria and randomly assigned to ACT $(n=20)$ and control $(n=20)$ groups using the random blocks (Figure 1). Accordingly, given the 0.95 confidence interval and the power of 0.80 , the sample size was determined 20 patients in each counseling, control group and based on the recommendation of reliable scientific references (24).

\section{Inclusion Criteria}

- $\quad$ Being within the age range of 18-45 years;

- Having a junior high school degree and above;

- Having an infertility history for at least 1 year;

- Not taking psychiatric and psychedelic drugs for at least 2 weeks before the trial;

- Not suffering from severe psychological or physical diseases;

- Not having a history of assisted reproductive technology.

\section{Exclusion Criteria}

- Being absent for 2 consecutive or non-consecutive sessions;

- Having a positive pregnancy test;

- Not doing the assignments and exercises at home for three consecutive or non-consecutive sessions;

- Taking psychiatric and psychedelic drugs during the trial;

- Experiencing stressful events during the study such as the death of the loved ones, divorce, and immigration.

The data collection instrument was FertiQoL Questionnaire. This questionnaire, designed by Boivin et al was applied to measure the quality of the life of infertile people and contained 36 questions. Each participant had to comment on each statement in a 4 -point (0-4) Likerttype scale as well (23).

FertiQoL was evaluated by 24 core items covering emotional, mind-body, relational, and social subscales each including six questions. Additionally, the treatment section encompassed 10 items covering environment (6 items) and tolerability (4 items) subscales. Two additional items evaluated the general quality of life and physical health and some questions were scored reversely. In addition, the overall score of the questionnaire was between 0 and 100 and higher scores indicated a more 


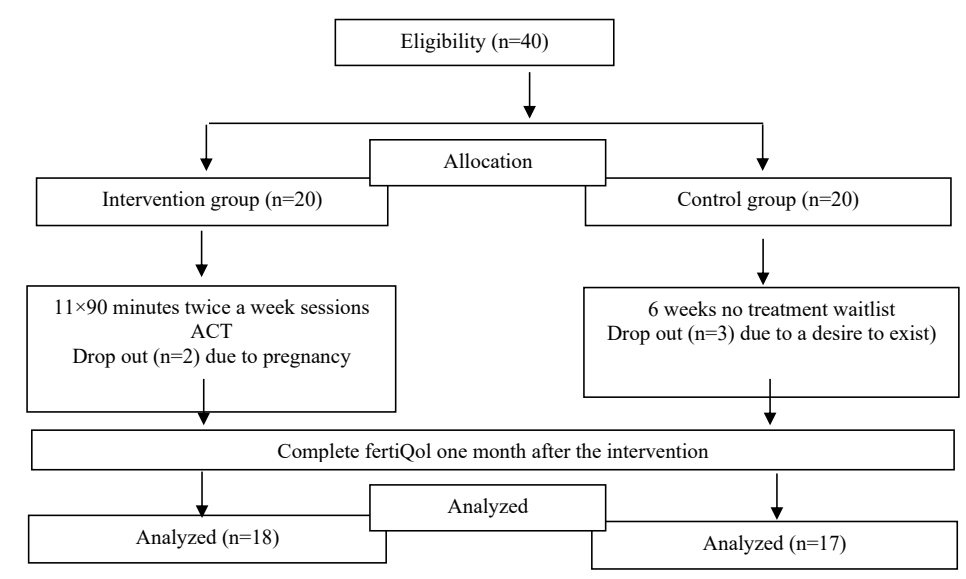

Figure 1. Flowchart of Participant's Progression Through the Study

desirable quality of life. The validity of this questionnaire was verified and the Cronbach alpha was satisfactory and in the range of 0.72-0.92 for subscales of treatment and the core FertiQoL (23). Further, the studies in Iran show acceptable validity and reliability for this scale, for example, in a study on 221 infertile women, the reliability coefficient was obtained as 0.90 for the whole questionnaire using the test-retest method (2).

The ACT group attended full eleven 90-minute counseling sessions twice a week (25) and a post-test was performed one month after the final session. The control group received no intervention and stayed in the waiting list. The content of the counseling sessions are summarized in Table 1 (26). It is noteworthy that considerations regarding informed consent and confidentiality were taken into account in all stages of the research. All the participants signed the informed consent forms and each participant received a code instead of her first and last name while their names along with their codes were kept confidential by the researcher. Eventually, the obtained data were analyzed using SPSS23 software by descriptive statistics, chi-square test, as well as independent and paired samples $t$ test. Type I error was considered as 5\% as well.

\section{Results}

The average age of women was $32.7( \pm 5.1)$ and $29.5 \pm$ (8.5) in the ACT and control groups respectively, and the difference was not statistically significant $(P=0.85)$. Further, the average age of the husbands was $36.8( \pm 4.8)$ and $33.4( \pm 6.2)$ in ACT and control groups, respectively $(P=0.84)$. Furthermore, the average duration of marriage in the ACT and control groups was $8.6( \pm 5.8)$ and $5.8( \pm 2.6)$, respectively, and the difference was not statistically significant $(P=0.87)$. Table 2 presents the other demographic characteristics of the groups and Table 3 provides the means and standard deviations of pre-test and post-test (one month after the intervention) and the components of the quality of life in ACT and control groups.

As shown in Table 3, there was a significant increase in the overall mean and the quality of life in the post-test (follow-up) of the ACT group compared to those in the pre-test whereas no significant change was observed in the post-test (follow-up) of the control group. Moreover, no significant difference was found between the means of the components of the quality of life in the ACT and control groups in the pre-test. However, the means of the components of the quality of life in the ACT and those

Table 1. Content of the Counseling Sessions

\begin{tabular}{ll}
\hline Sessions & Content \\
\hline First & 1. Briefing and introduction \\
Second & 1. Familiarity with the concept of creative helplessness; 2. Hungry tiger metaphor \\
Third & 1. Creative hopelessness continued 2. Tug-of-war with a monster \\
Fourth & 1. Control is a problem; 2. Polygraph metaphor \\
Fifth & 1. Control is a problem; 2. Two scales metaphor; 3. The key to fighting and clean versus dirty discomfort \\
Sixth & 1. Control is a problem; 2. Chocolate cake metaphor; 3. Mindfulness with conscious breathing exercises \\
Seventh & 1. Defusin from unpleasant thoughts and feelings; 2. Numbers metaphor; 3.Passengers on the bus metaphor \\
Eighth & 1. Defusion; 2. Willingness and acceptance; 3. Lion metaphor; 4. Parade practice; 5. Mindfulness training \\
Ninth & 1. Defusion; 2. Self as the context; 3. Gravestone practice; 4. Relation between goals and values \\
Tenth & 1. Values review; 2. Self as the context; 3. Chessboard metaphor; 4. Beggar metaphor; 5. Stating values and commitment \\
Eleventh & 1. Reviewing and summarizing the materials \\
\hline
\end{tabular}


Table 2. Characteristics of the Subjects in ACT and Control Groups

\begin{tabular}{|c|c|c|c|}
\hline Variables & $\begin{array}{c}\text { ACT } \\
\text { No. (\%) }\end{array}$ & $\begin{array}{l}\text { Control } \\
\text { No. (\%) }\end{array}$ & $P$ Value \\
\hline Participants' education level & & & $0.6^{*}$ \\
\hline Elementary & $1(5.6)$ & $2(11.8)$ & \\
\hline Junior high school & $3(16.6)$ & $1(5.8)$ & \\
\hline High school diploma & $5(27.8)$ & $6(35.3)$ & \\
\hline Collegiate & $9(50)$ & $8(47.1)$ & \\
\hline Participants' working status & & & $0.3^{*}$ \\
\hline Housewife & $17(94.4)$ & $16(94.1)$ & \\
\hline Hired & $1(5.6)$ & $1(5.9)$ & \\
\hline Spouses' Education level & & & $0.6^{*}$ \\
\hline Elementary & $3(16.7)$ & $0(0)$ & \\
\hline Junior high school & $4(22.2)$ & $4(18.8)$ & \\
\hline High school diploma & $6(33.3)$ & $6(37.7)$ & \\
\hline Collegiate & $5(27.8)$ & $7(43.7)$ & \\
\hline Spouses' working status & & & $0.5^{*}$ \\
\hline Employee & $16(94.1)$ & $16(94.1)$ & \\
\hline Unemployed & $2(5.9)$ & $1(5.9)$ & \\
\hline Location & & & $0.9^{*}$ \\
\hline Urban & $17(94.4)$ & $15(93.8)$ & \\
\hline Rural & $1(5.6)$ & $2(6.2)$ & \\
\hline Economic status & & & $0.014^{*}$ \\
\hline Good & $1(5.6)$ & $3(17.6)$ & \\
\hline Moderate & $9(50)$ & $11(64.7)$ & \\
\hline Poor & $8(44.4)$ & $3(17.7)$ & \\
\hline
\end{tabular}

ACT, acceptance and commitment therapy.

*Chi-square test. in the control group significantly differed in the post-test (follow-up). Therefore, according to the results of the study, the first and third hypotheses are rejected while the second one is verified.

\section{Discussion}

This clinical trial examined the effect of ACT on the quality of life of infertile women during treatment. Based on our findings, no significant difference was observed between the mean score of the quality of life between the 2 groups before the intervention. However, the results showed that ACT was effective in improving the quality of life and its components in infertile women who were evaluated after one month.

This result is indirectly compatible with the findings of several previous studies $(15,16,22)$ and directly with the results of some other studies $(20,21)$, indicating that ACT was as an effective therapy for reducing infertility-related stressful factors. Other studies also confirmed the effect of ACT. For example, ACT was found to reduce depression in people who were unable to work due to disability or illness (27). Additionally, this type of therapy played a role in reducing depressive symptoms and improving cognitive emotion regulation strategies in depressive students (26). Based on the results of another study, ACT contributed to increasing the quality of life, general health, vitality, and the mental health of infertile women (12).

Similarly, ACT involves cognitive-behavioral problem solving, moment-to-moment awareness of emotions (mindfulness), and the unconditional acceptance of the problem and helps individuals to improve their problemsolving skills. These patients have multiple cognitive

Table 3. Mean Subcategories of the Quality of Life Before and One Month After Intervention Among ACT and Control groups

\begin{tabular}{|c|c|c|c|c|}
\hline \multirow[b]{2}{*}{ Quality of Life Categories } & \multirow[b]{2}{*}{ Time } & \multicolumn{2}{|c|}{ Groups } & \multirow[b]{2}{*}{$P$ Value ${ }^{*}$} \\
\hline & & $\begin{array}{c}\text { ACT } \\
\text { Mean ( } \pm S D)\end{array}$ & $\begin{array}{c}\text { Control } \\
\text { Mean }( \pm S D)\end{array}$ & \\
\hline \multirow{2}{*}{ Total FertiQoL } & Pretest & $53.7( \pm 8.6)$ & $55.2( \pm 12.4)$ & 0.6 \\
\hline & Posttest & $69.3( \pm 9.6)$ & $55.1( \pm 12)$ & 0.001 \\
\hline \multirow{2}{*}{ Mind/body } & Pretest & $55.1( \pm 15.8)$ & $66.4( \pm 17.3)$ & 0.52 \\
\hline & Posttest & $79.1( \pm 16.6)$ & $65.4( \pm 18.2)$ & 0.02 \\
\hline \multirow{2}{*}{ Emotional } & Pretest & $40.7( \pm 15.8)$ & $49.3( \pm 22.3)$ & 0.1 \\
\hline & Posttest & $72.9( \pm 14.1)$ & $48.5( \pm 20.8)$ & 0.001 \\
\hline \multirow{2}{*}{ Relational } & Pretest & $67.6( \pm 18.7)$ & $66.9( \pm 13.5)$ & 0.9 \\
\hline & Posttest & $83.1( \pm 13.6)$ & $64( \pm 11)$ & 0.001 \\
\hline \multirow{2}{*}{ Social } & Pretest & $61.9( \pm 17.3)$ & $60.7( \pm 18.4)$ & 0.8 \\
\hline & Posttest & $68.9( \pm 18.9)$ & $54.7( \pm 14.4)$ & 0.018 \\
\hline \multirow{2}{*}{ Environment } & Pretest & $52.5( \pm 13.3)$ & $48.8( \pm 16.3)$ & 0.4 \\
\hline & Posttest & $58.3( \pm 11.8)$ & $52.9( \pm 12)$ & 0.1 \\
\hline \multirow{2}{*}{ Tolerability } & Pretest & $49.5( \pm 16.3)$ & $52.5( \pm 14.8)$ & 0.5 \\
\hline & Posttest & $69( \pm 12.7)$ & $53.2( \pm 18.2)$ & 0.005 \\
\hline
\end{tabular}

ACT: Acceptance and commitment therapy; SD: Standard deviation; FertiQoL: Fertility quality of life

*Independent sample $t$ test. 
distortions and inefficient thoughts, thus the activation of these thoughts makes them focus on themselves, feel worthless and hopeless, and experience low mood, and finally, deteriorates their symptoms. Teaching different methods of challenging by unreasonable thoughts and choosing an appropriate approach to the problem, which is known as "cognitive defusion" in ACT, can affect the quality of the life of infertile couples through affecting these aspects (11)

The physical aspect (i.e., general health, physical role, and bodily pain) is considered as one of the important dimensions of the quality of life. Based on the results of a study, infertile people have problems which are related to the physical dimension (28). As no research has not specifically investigated the effectiveness of ACT in dimensions related to quality of life of infertile couples, it can be generally concluded that in case of effectiveness of these training method for improving physical dimension, infertility and its subsequent stress can cause physiological stress. This stress and pain caused by different types of infertility treatments can create a lot of health problems (20). ACT increases acceptance and reduces cognitive avoidance, leading to reduced infertility, physiological stress, and physical pain (29).

In addition, mental health (i.e., emotional role, vitality, and social functioning) is regarded as another important dimension of the quality of life. The results showed ACT led to an improvement in this dimension among the infertile women in the intervention group as compared to the control group. These results are in line with those of the other studies (30-32), indicating that the third wave of behavioral treatments is effective in reducing the impulsive behaviors which disturb the quality of life such as mood and emotional disorders, anger, and emotional instability. Based on the ACT, increased cognitive defusion and conscious acceptance help women and couples to experience negative interactions and thoughts in a new way and reduce their negative actions. They further learn to struggle with and accept the situations and thoughts that they used to avoid. The clarification of relational values and committed action in the service of these values provide the couples with the chance to act in a way to lead their lives toward satisfaction and relation, reducing individual and physiological stress.

According to the findings of the studies by Peterson and Eifert, as well as Peterson et al, therapeutic strategies based on cognitive-behavioral and patient-centered approach include those psychological interventions which focus on improvements in

- Attributional styles;

- Mindfulness;

- Challenging through unreasonable beliefs;

- Empathy;

- The acceptance of the problem;

- Muscle relaxation;

- Teaching problem-solving skills, meditation, biofeedback, guided mental imagery, and coping strategies.

The above-mentioned strategies not only decrease the negative emotional consequences of different diseases and disorders but also help to increase the commitment to therapeutic advice $(20,21)$. Therefore, therapists are dealing with infertile couples are recommended to use ACT including mental acceptance, cognitive diffusion, and tracking behaviors guided by values in their future trials in order to reduce these couples suffering.

\section{Conclusions}

Overall, the treatment process and the obtained results demonstrated that ACT could be an effective treatment for infertile women. Thus, further extensive studies are required to investigate the differences and similarities of ACT with other therapies on the quality of life and the effect of this approach on the outcome of infertility treatment. Due to time limitations and the lack of access to the clients, the study failed to conduct a longer follow-up and thus there is no information on the stability of effect of ACT in the long run. Despite the efforts of the researchers to remove or control confounding variables about personal differences, psychological characteristics of individuals, behavioral discrepancy among the midwife, gynecologist and other members of the treatment team in visit with infertile women during the intervention, could not be controlled. Based on the findings of this research, ACT was generally effective in the quality of life. Therefore, this type of therapy can be utilized as an effective treatment for solving marital problems in infertility, counseling, and psychotherapy clinics.

\section{Conflict of Interests}

Authors declare that they have no conflict of interests.

\section{Ethical Issues}

This study was approved by the Ethics Committee of Arak University of Medical Sciences (ethic No. 1395.153). In addition, it was registered in the Iranian Registry of Clinical Trials website (identifier: IRCT2016082129433N1).

\section{Financial Support}

Arak University of Medical Sciences (grant No. 1188) provided financial support.

\section{Acknowledgments}

We would like to thank the Research Council of Arak University of Medical Sciences for their financial support, as well as all the personnel of Omid Rouyn Infertility Center in Arak, Iran. Special thanks also go to the infertile women who participated in the study and all those who collaborated with the researchers in this study.

\section{References}

1. Zegers-Hochschild F, Adamson GD, de Mouzon J, et 
al. International Committee for Monitoring Assisted Reproductive Technology (ICMART) and the World Health Organization (WHO) revised glossary of ART terminology, 2009. Fertil Steril. 2009;92(5):1520-1524. doi:10.1016/j. fertnstert.2009.09.009

2. Maroufizadeh S, Ghaheri A, Amini P, Samani RO. Psychometric Properties of The Fertility Quality of Life Instrument in Infertile Iranian Women. Int J Fertil Steril. 2017;10(4):371-379.

3. Anwar S, Anwar A. Infertility: A review on causes, treatment and management. Women's Health \& Gynecology. 2016;2(6):1-5.

4. Onat G, Aba YA. The Effects of a Healthy Lifestyle and of Anxiety Levels on IVF Outcomes. Afr J Reprod Health. 2015;19(4):92-101.

5. Sehhatie Shafaie F, Mirghafourvand M, Rahimi M. Perceived stress and its social-individual predicors among infertile couples referring to infertility center of Alzahra hospital in Tabriz in 2013. International Journal of Women's Health and Reproduction Sciences. 2014;2(5):291-296. doi:10.15296/ijwhr.2014.47

6. Ismail $\mathrm{N}$, Moussa A. Coping strategies and quality of life among infertile women in Damanhour City. Journal of Nursing and Health Science. 2017;6(2):31-45. doi:10.9790/1959-0602083145

7. Dattijo 1, Andreadis N, Aminu B, Umar N, Black K. Knowledge of infertility among infertile women in Bauchi, Northern Nigeria. International Journal of Women's Health and Reproduction Sciences. 2016;4(3):103-109. doi:10.15296/ijwhr.2016.25

8. Dyer SJ, Abrahams N, Mokoena NE, Lombard CJ, van der Spuy ZM. Psychological distress among women suffering from couple infertility in South Africa: a quantitative assessment. Hum Reprod. 2005;20(7):1938-1943. doi:10.1093/humrep/deh845

9. Aliyeh G, Laya F. Quality of life and its correlates among a group of infertile Iranian women. Med Sci Monit. 2007;13(7):CR313-317.

10. Fuh JL, Wang SJ, Lu SR, Juang KD. Assessing quality of life for adolescents in Taiwan. Psychiatry Clin Neurosci. 2005;59(1):11-18. doi:10.1111/j.1323-1316.2005.01306.x

11. Tiu MM, Hong JY, Cheng VS, Kam CY, Ng BT. Lived experience of infertility among Hong Kong Chinese women. Int J Qual Stud Health Well-being. 2018;13(1):1554023. doi: $10.1080 / 17482631.2018 .1554023$

12. Brown M, Glendenning A, Hoon AE, John A. Effectiveness of Web-Delivered Acceptance and Commitment Therapy in Relation to Mental Health and Well-Being: A Systematic Review and Meta-Analysis. J Med Internet Res. 2016;18(8):e221. doi:10.2196/jmir.6200

13. Whiting DL, Simpson GK, McLeod HJ, Deane FP, Ciarrochi J. Acceptance and commitment therapy (ACT) for psychological adjustment after traumatic brain injury: reporting the protocol for a randomised controlled trial. Brain Impair. 2012;13(3):360-376. doi:10.1017/ BrImp.2012.28

14. Yang SY, Moss-Morris R, McCracken LM. iACT-CEL: A Feasibility Trial of a Face-to-Face and Internet-Based Acceptance and Commitment Therapy Intervention for Chronic Pain in Singapore. Pain Res Treat.
2017;2017:6916915. doi:10.1155/2017/6916915

15. Levitt JT, Brown TA, Orsillo SM, Barlow DH. The effects of acceptance versus suppression of emotion on subjective and psychophysiological response to carbon dioxide challenge in patients with panic disorder. Behav Ther. 2004;35(4):747-766. doi:10.1016/S0005-7894(04)80018-2

16. Eifert GH, Forsyth JP, Arch J, Espejo E, Keller M, Langer D. Acceptance and Commitment Therapy for Anxiety Disorders: Three Case Studies Exemplifying a Unified Treatment Protocol. Cogn Behav Pract. 2009;16(4):368385. doi:10.1016/j.cbpra.2009.06.001

17. Hayes SC, Luoma JB, Bond FW, Masuda A, Lillis J. Acceptance and commitment therapy: model, processes and outcomes. Behav Res Ther. 2006;44(1):1-25. doi:10.1016/j. brat.2005.06.006

18. Saedy M, Kooshki S, Jamali Firouzabadi M, Emamipour S, Rezaei Ardani A. Effectiveness of Acceptance-Commitment Therapy on Anxiety and Depression among Patients on Methadone Treatment: A Pilot Study. Iran J Psychiatry Behav Sci. 2015;9(1):e222. doi:10.17795/ijpbs222

19. Feliu-Soler A, Montesinos F, Gutiérrez-Martínez O, Scott W, McCracken LM, Luciano JV. Current status of acceptance and commitment therapy for chronic pain: a narrative review. J Pain Res. 2018;11:2145-2159. doi:10.2147/jpr. s144631

20. Peterson BD, Eifert GH. Using acceptance and commitment therapy to treat infertility stress. Cogn Behav Pract. 2011;18(4):577-587. doi:10.1016/j.cbpra.2010.03.004

21. Peterson BD, Eifert GH, Feingold T, Davidson S. Using acceptance and commitment therapy to treat distressed couples: A case study with two couples. Cogn Behav Pract. 2009;16(4):430-442. doi:10.1016/j.cbpra.2008.12.009

22. Zettle RD. Acceptance and commitment therapy (ACT) vs. systematic desensitization in treatment of mathematics anxiety. Psychol Rec. 2003;53(2):197-215. doi:10.1007/ bf03395440

23. Boivin J, Takefman J, Braverman A. The Fertility Quality of Life (FertiQoL) tool: development and general psychometric properties. Fertil Steril. 2011;96(2):409-415. e403. doi:10.1016/j.fertnstert.2011.02.046

24. Seyedi Asl ST, Sadeghi K, Bakhtiari M, Ahmadi SM, Nazari Anamagh A, Khayatan T. Effect of Group Positive Psychotherapy on Improvement of Life Satisfaction and The Quality of Life in Infertile Woman. Int J Fertil Steril. 2016;10(1):105-112.

25. Batink T, Bakker J, Vaessen $\mathrm{T}$, et al. Acceptance and Commitment Therapy in Daily Life Training: A Feasibility Study of an mHealth Intervention. JMIR Mhealth Uhealth. 2016;4(3):e103. doi:10.2196/mhealth.5437

26. Hamid N, Boolaghi Y, Kiani Moghadam AS. The Efficacy of acceptance and commitment based therapy (ACT) on depressive symptoms and cognitive emotion regulation strategies in depressive students. Int J Psychol. 2018;12(1):529. doi:10.24200/ijpb.2018.58144

27. Folke F, Parling T, Melin L. Acceptance and commitment therapy for depression: A preliminary randomized clinical trial for unemployed on long-term sick leave. Cogn Behav Pract. 2012;19(4):583-594. doi:10.1016/j.cbpra.2012.01.002

28. Namdar A, Naghizadeh MM, Zamani M, Yaghmaei F, Sameni MH. Quality of life and general health of infertile 
women. Health Qual Life Outcomes. 2017;15(1):139. doi:10.1186/s12955-017-0712-y

29. Jamshidian Qalehshahi P, Aghaei A, Golparvar M. Comparing the effect of Iranian positive therapy and acceptance-commitment therapy on depression, anxiety and stress of infertile women in Isfahan city. Journal of Health Promotion Management. 2017;6(8):8-15.

30. Kröger C, Schweiger U, Sipos V, et al. Effectiveness of dialectical behaviour therapy for borderline personality disorder in an inpatient setting. Behav Res Ther.
2006;44(8):1211-1217. doi:10.1016/j.brat.2005.08.012

31. McQuillan A, Nicastro R, Guenot F, Girard M, Lissner C, Ferrero F. Intensive dialectical behavior therapy for outpatients with borderline personality disorder who are in crisis. Psychiatr Serv. 2005;56(2):193-197. doi:10.1176/appi. ps.56.2.193

32. Miller AL, Rathus J, Linehan MM. Dialectical Behavior Therapy with Suicidal Adolescents. New York: Guilford Press; 2007. p. 221-254.

(C) 2019 The Author (s); This is an open-access article distributed under the terms of the Creative Commons Attribution License (http://creativecommons.org/licenses/by/4.0), which permits unrestricted use, distribution, and reproduction in any medium, provided the original work is properly cited. 